\title{
Parapharyngeal Tumour - A Study of 30 Cases
}

\author{
Bithi Bhowmik ${ }^{1}$, Miraj Ahmed ${ }^{2}$, Debesh Chandra Talukder ${ }^{3}$, Belayet Hossain Siddique ${ }^{4}$
}

\begin{abstract}
Background: Parapharyngeal tumours are a group of rare neoplasms arising from structures within the parapharyngeal space. The complex anatomical and pathological consideration of this region often present a substantial challenge to the otolaryngologist and head-neck surgeons in the evaluation and management of these lesions. The majority of tumours arising in the parapharyngeal space are benign and surgical resection is the mainstay of treatment Objective: To determine frequency, demography, histological pattern and management of parapharyngeal tumour. Materials and method: A cross sectional study was carried out from January 2007 to December 2007. Total 30 cases were selected from Bangabandhu Sheikh Mujib Medical University, Dhaka, Bangladesh, Dhaka Medical College Hospital, Dhaka, Bangladesh and Sir Salimullah Medical College Mitford Hospital, Dhaka, Bangladesh. Results: In this study $37 \%$ patients were in the fourth decade. Among the study subjects, 21(70\%) were male and 9(30\%) were female. Most of the patients presented with neck swelling (66\%) followed by oropharyngeal swelling (50\%). In this study salivary gland tumours were the highest (47\%) in number, neurogenic tumours constituted $40 \%$ and chemodectomas were 13\%. Histopathologically 80\% tumours were benign. Both transparotid and inferior approaches were used for surgical resection in each $40 \%$ of cases. Conclusion: Most of the cases were benign and detected around fourth decade of life with male predominance. Surgical resection was the lone treatment for the cases with few post operative complications.
\end{abstract}

Keywords: Parapharyngeal space tumour.

Delta Med Col J. Jan 2016;4(1):18-23

\section{Introduction}

Parapharyngeal tumours are a group of rare neoplasms. They constitute less than $0.5 \%$ of head-neck region tumours. ${ }^{1}$ These neoplastic processes represent wide variety of both benign and malignant lesions arising from structures within the parapharyngeal space. The complex anatomical and pathological consideration of this region often present a substantial challenge to the otolaryngologist and head-neck surgeons in the evaluation and management of these lesions. The

1. Consultant, Dept. of ENT \& Head-Neck Surgery, Asgar Ali Hospital, Gandaria, Dhaka, Bangladesh.

2. Medical Officer, Dept. of ENT \& Head Neck Surgery, Sir Salimullah Medical College Mitford Hospital, Dhaka, Bangladesh.

3. Associate Professor, Dept. of ENT \& Head-Neck Surgery, Dhaka Medical College, Dhaka, Bangladesh.

4. Professor of Otolaryngology, Head of the Head-Neck \& Reconstructive Surgery Unit, Bangabandhu Sheikh Mujib Medical University, Dhaka, Bangladesh.

Correspondence: . Dr. Bithi Bhowmik. e-mail: bithi.bhowmik059@yahoo.com 
majority of tumours arising in the parapharyngeal space are benign and surgical resection is the mainstay of therapy. ${ }^{2}$

The parapharyngeal space lies adjacent to the nasopharynx and oropharynx between the base of the skull and the hyoid bone. It is a potential space bounded by the fascial planes of the head and neck. The space is traversed by the styloid process and its attachments. The styloid process divides this space into the prestyloid and poststyloid compartments. The prestyloid compartment contains the parotid gland and some lymph nodes. The poststyloid compartment contains the internal jugular vein, internal carotid artery, lower cranial nerves (IX, X, XI, XII), the cervical sympathetic chain and lymph nodes. ${ }^{3}$

Tumours cause a bulge in lateral pharyngeal wall and distort the pillars and soft palate and thus mimic neoplasm of the oropharynx. Commonly seen tumours are those from the deep lobe of parotid, neurogenic tumours namely schwannomas, neurofibromas and ganglion tumours, chemodectomas namely carotid body tumours, glomus vagale tumour, glomus jugulare tumour, lipoma and aneurysm of internal carotid artery. ${ }^{4}$ The symptoms vary with the size of the tumour and its histological character. These include sore throat, difficulty in swallowing, fullness in the ear, change in voice and symptoms secondary to paralysis of cranial nerves. ${ }^{5}$

CT scan in axial plane with $5 \mathrm{~mm}$ contiguous sections and contrast enhancement is the usual means of investigation. In selected cases, further sections in the coronal plane may be an advantage. However MR is now becoming the preferred means of investigating these tumours with both contrast enhancement and MR angiography (MRA) being used. 6 Fine needle aspiration cytology (FNAC) has traditionally played an important role in the work up of a neck lump. ${ }^{3}$

Pathologically, there are three main groups of primary tumours in the parapharyngeal space - salivary gland tumour, neurogenic tumours and paragangliomas. ${ }^{3}$ The commonest tumour in the salivary gland group is those arising from the deep lobe of the parotid gland. These may be localized to the deep lobe, be of dumb-bell shape or be part of a malignant infiltration of the whole gland. The dumb-bell shape is the result of constriction of the tumour in the region of stylomandibular ligament. ${ }^{3}$ In neurogenic tumour group, the commonest are the neurilemmomas. They usually do not present with any associated cranial nerve palsy unless are malignant. Others are neurofibromas. ${ }^{7}$

Basic approaches to the parapharyngeal spaces ${ }^{8}$ are -

a. Transparotid

b. Anterior transantral approach

c. Superior approach

d. Inferior approach

e. Midline transmandibular oropharyngeal approach

f. Extended anterolateral approach.

This study on parapharyngeal masses happens to be the first one on this subject in our country. Interest in parapharyngeal space is recently on the rise worldwide as the new cross sectional imaging technique get popularized. ${ }^{9}$ This is an organized approach to deal with these tumours as a different entity and not just as one of the neck masses. The aim of the study was to find the frequency, demography, histological pattern and management of parapharyngeal tumour and to compare with available other reports.

\section{Materials and method}

This cross sectional study was carried out in Bangabandhu Sheikh Mujib Medical University, Dhaka, Bangladesh, Dhaka Medical College Hospital, Dhaka, Bangladesh and Sir Salimullah 
Medical College Mitford Hospital, Dhaka, Bangladesh between January 2007 to December 2007. Total 30 subjects of both sex were included in this study. All the study subjects were clinically and radiologically diagnosed as having parapharyngeal tumour and all the subjects had to undergo surgical intervention.

\section{Inclusion criteria}

1. Patients having definite clinical evidence of bulge in the lateral pharyngeal wall with intact surface mucosa.

2. Clinically and radiologically diagnosed cases of parapharyngeal space tumours.

\section{Exclusion criteria}

1. Tumours from infratemporal fossa.

2. Tumours extending from retromolar space.

3. Tumours arising from retropharyngeal space.

4. Patient having definite clinical evidence of primary in tonsil, posterior pharyngeal wall, larynx and pharynx with secondaries in the neck extending into the parapharyngeal space.

\section{Results}

In this series of 30 patients of parapharyngeal space tumours, the minimum age was 15 years, maximum age was 70 years and average age was 39 years. Maximum (36.67\%) patients were in the $4^{\text {th }}$ decade.

Table I: Age distribution of the study subjects $(\mathrm{N}=30)$

\begin{tabular}{lcc}
\hline Age group (year) & Number of patients & Percentage \\
\hline Below 30 & 9 & 30.00 \\
$31-40$ & 3 & 10.00 \\
$41-50$ & 11 & 36.67 \\
$51-60$ & 6 & 20.00 \\
$61-70$ & 1 & 3.33 \\
\hline
\end{tabular}

A male preponderance was observed in this study.
Table II: Sex distribution of the study subjects (N=30)

\begin{tabular}{lcc}
\hline Sex & Number of Patient & Percentage \\
\hline Male & 21 & 70 \\
Female & 9 & 30 \\
\hline
\end{tabular}

The commonest presenting symptom of a tumour in parapharyngeal space was painless neck swelling, as in 20 of our patients.

Table III: Clinical presentations of the study subjects $(\mathbf{N}=\mathbf{3 0})$

\begin{tabular}{lcc}
\hline Symptoms & Number of patient* & percentage \\
\hline Neck swelling & 20 & 66.37 \\
Oropharyngeal swelling & 15 & 50.00 \\
Dysphonia & 11 & 36.67 \\
Dysphagia & 10 & 33.33 \\
Fullness of the ear & 1 & 3.33 \\
Cranial nerve palsy & 1 & 3.33 \\
Sore throat & 3 & 10.00 \\
Cervical pain & 1 & 3.33 \\
\hline * Multiple responses & &
\end{tabular}

Pleomorphic adenoma of the deep lobe of parotid gland and neurofibroma were the most numerous tumours in this study.

Table IV: Histopathological diagnosis $(\mathbf{N}=\mathbf{3 0})$

\begin{tabular}{lcc}
\hline Types of tumour & Number of patients & Percentage \\
\hline $\begin{array}{l}\text { Pleomorphic adenoma of } \\
\text { deep lobe of parotid }\end{array}$ & 7 & 23.33 \\
$\begin{array}{l}\text { Ectopic salivary tumour } \\
\quad \text { Mucoepidermoid carcinoma }\end{array}$ & 4 & \\
$\quad$ Adenocarcinoma & & 13.33 \\
Adenoid cystic carcinoma of & 2 & 6.67 \\
deep lobe of parotid & & \\
Neurilemmoma & 1 & 3.33 \\
Neurofibroma & 5 & 16.67 \\
Chemodectoma & 7 & 23.33 \\
$\quad$ Carotid body tumour & 3 & 10.00 \\
$\quad$ Vagal body tumour & 1 & 3.33 \\
\hline
\end{tabular}

Table VI shows that transparotid and inferior approaches were the most often performed surgical approaches in this study

Table VI: Surgical approaches $(\mathbf{N}=\mathbf{3 0})$

\begin{tabular}{lcc}
\hline Type & Number of patients & Percentage \\
\hline $\begin{array}{l}\text { Transparotid } \\
\text { Inferior with or without }\end{array}$ & 12 & 40 \\
$\begin{array}{l}\text { angle mandibulotomy } \\
\text { Midline transmandibular }\end{array}$ & 2 & 40 \\
$\begin{array}{l}\text { oropharyngeal } \\
\text { Per oral }\end{array}$ & 4 & 7 \\
\hline
\end{tabular}




\section{Discussion}

This study as it comprises of cases attending hospital within one year of time limit only, is not large enough to represent the scenario with more accuracy. But since it was carried out in all three major tertiary health care institutes of the capital city of a country with 140 million population, cases were not difficult to find. Fresh cases were however sparse as the disease is relatively rare.

The age of patients ranged from 15 to 70 years. The highest incidence was found in the $4^{\text {th }}$ decade (37\%) of life. This finding is comparable to that described by Stanley ${ }^{10}$ and Bozza et al. ${ }^{11}$

Males were more affected in this study. José et al. ${ }^{1}$ reported a male preponderance. Maran et al. ${ }^{12}$ however found no sex predominance. Pang et al. ${ }^{3}$ observed no sex predominance in their series too.

Clinical presentation of the patients was diverse. Most patients presented with multiple complaints. The most common (66\%) presenting symptom was of a painless neck swelling in this study followed by oropharyngeal bulging. Only one patient presented with ear symptoms. He had conductive hearing loss due to middle ear effusion subsequent to Eustachian tube blockade caused by the large tumour indenting the nasopharynx. ${ }^{13}$ These tumours are usually painless because of their expansile nature; however, pain must raise a strong suspicion of malignancy. Speech or swallowing problems may result from lower cranial nerve involvement. It occurs more commonly due to displacement of the lateral pharyngeal wall and the tonsil. In our study, one patient had tonsillectomy performed for a unilateral "tonsillar" mass. One patient had an incision and drainage performed earlier for a suspected left "quinsy".

In this study salivary gland origin tumours were of the highest in number. In $36.67 \%$ cases the tumours arose from the deep lobe of the parotid gland. Maran et al. ${ }^{12}$ observed that deep lobe tumours of the parotid gland account for 12 to $25 \%$ all parotid tumours. In 2 other series the commonest tumours were benign mixed salivary tumours $(33.3 \%$ and $43 \%) .{ }^{14,19}$

The present study depicted $23 \%$ incidence of benign mixed salivary tumour. The cases of ectopic salivary gland tumour were diagnosed as an adenocarcinoma and a mucoepidermoid carcinoma. Tumour arising from the minor salivary gland tissue within the parapharyngeal space fat has also been documented. These tumours have a higher likelihood of malignancy. ${ }^{3}$

Thirteen of the cases were neurogenic tumours. The figure as found by José et al. ${ }^{1}$ was $35.3 \%$ in this study. Bahadur et al. ${ }^{5}$ reported 13 cases of neurofibroma in their series of 36 cases which constitutes $36 \%$ of total cases.

Majority of the neoplasms were of benign variety. In our study 24 out of 30 patients $(80 \%)$ had benign tumours. The data from the literature suggests that $80 \%$ of these lesions are benign. ${ }^{5}$

In the present series 5 patients had neurilemmomas. In one case the tumour was attached to hypoglossal nerve from which it could not be freed. Patient had persistent post operative $12^{\text {th }}$ nerve paralysis. In another case the fibres of the $12^{\text {th }}$ nerve were found stretched over the capsule of the tumour from which the tumour could be dissected easily. This patient had post-operative $12^{\text {th }}$ nerve paresis which improved subsequently. In one case the tumour was attached to the vagus nerve from which the tumour could not be freed easily but patient did not have post-operative vagal paralysis. In one case the tumour was arising from cervical sympathetic chain. This patient had ipsilateral ptosis after one month of surgery. A patient who had neurofibroma also developed vagal and cervical sympathetic paralysis after 24 hours of surgery.

We had 4 cases of chemodectomas. One of the 3 cases was of carotid body tumours and one of vagal body tumour. Carotid angiogram was done and urinary catecholamine was assessed. Ten to 
$50 \%$ of these tumours can undergo malignant change. Hence biopsy of a tumour from oral side is not advised. ${ }^{17}$ All the cases could be excised successfully. There was no recurrence observed. Conely ${ }^{16}$ described four situations where they should be removed. Those that are proven histologically and clinically to be malignant and that are resectable, those that show an aggressive pattern regardless of histological interpretation; those patients in good health, who present with small or medium size tumour and those tumours which have extended into the pharynx or plate and are interfering with swallowing, speaking or breathing.

Surgical approaches were considered according to the size and site of the lesion. Most cases in this study were operated by the transparotid and the inferior approach. Forty percent of total patients were in each group. José et al. ${ }^{1}$ used inferior approach in $65.4 \%$ cases in his series. Pang et al. ${ }^{3}$ also used this approach in most of his patients. Bahadur et al. ${ }^{5}$ used transparotid approach for deep lobe tumours with excellent post operative results.

Mandibulotomy was required in 10 cases. Blood transfusion was given in 2 patients. The mean surgical time was three hours with a range of one to eight hours. The average number of days of drainage was 3.5 and mean length of hospital stay was 5.3 days. Preoperative assessment by FNAC was confirmed in all cases by histopathology examination. Post operative complications were few. Of the 14 cases that had total parotidectomy, three experienced facial weakness, but had complete recovery.

\section{Conclusion}

Parapharyngeal space tumours are rare and mostly benign. Moreover, they are difficult to diagnose early as they produce symptoms slowly. Surgical resection being the mainstay of therapy, tumours of this complex anatomical region calls for careful preoperative planning and great skill for selecting the right approach and for management with minimal morbidity and recurrence. The present study unfurls the need to carry on with further research into this particular area.

\section{References}

1. José TA, Santos MA, Albina A, Rui Carlos S Jr., Gilson B, de Toledo LH, et al. Parapharyngeal Space Tumors: Considerations in 26 Cases. Sao Paulo Med J. 1999;117(1):34-37.

2. Kennedy K, Pou A, editors. Parapharyngeal Space Neoplasms. UTMB Dept. of Otolaryngology Grand Rounds Presentation; 1998 Feb 18.

3. Pang KP, Goh CHK, Tan HM. Parapharyngeal Space Tumours: An 18 Year Review. The Journal of Laryngology and Otology. 2002;116(3):170-75.

4. Shaheen O. Tumours of the Infratemporal Fossa and Parapharyngeal Space. In: Hibbert J, editor. Scott-Brown's Otolaryngology. $6^{\text {th }}$ ed. Oxford: Butterworth-Heinemann; 1997. p11-19.

5. Bahadur S, Tandon DA, Kacker SK, Mishra NK. Surgery for Parapharyngeal Space Tumours. Indian Journal of Otolaryngology and Head and Neck surgery. 1993;2(1):35-37.

6. Rheops PD. Radiological Examination. In: Hibbert J, editor. Scott-Brown's Otolaryngology. $6^{\text {th }}$ ed. Oxford: Butterworth-Heinemann; 1997.

7. Raney RW. Parapharyngeal Masses: Their Diagnosis and Management. Grand Rounds Archive from Baylor College of Medicine. Houston, Texas; 1994 June 23.

8. Patey DH, Thackray AC. The Pathological Anatomy and Treatment of Parotid Tumour with Retropharyngeal Extension (Dumb-bell Tumours). British Journal of Surgery. 1956;44:352-58.

9. Dhingra PL. Tumours of Oropharynx. Diseases of Ear, Nose \& Throat. $3^{\text {rd }}$ ed. New Delhi: Elsevier; 2004. p.327.

10. Stanley RE. Parapharyngeal Space Tumours. Ann Acad Med. 1991;20:589-96.

11. Bozza F, Vigili MG, Ruscito P, Marzetti A, Marzetti F. Surgical Management of Parapharyngeal Space Tumours: Results of 10 Year Follow-up. Acta Otorhinolaryngol Ital. 2009;29(1):10-15. 
12. Maran AGD, Mackenzie IJ, Murray JAMS. The Parapharyngeal Space. Journal of Laryngology and Otolaryngology. 1984;98:371-80.

13. Heeneman A, Gilbert J, Rood SR. The Parapharyngeal Space, a Self Instructional Package. American Academy of Otolaryngology. 1980;11.

14. Work WP. Tumours of Parapharyngeal Space, Transactions. American Academy of Ophthalmology and Otolaryngology. 1969;73: 389-94.
15. Goldman NC, Hardcastle B. Fibrosarcoma of the Parapharyngeal Space. Laryngoscope. 1970;80:1809-15.

16. Conely JJ. Search for the Identification of the Facial Nerve. British Journal of Surgery. 1978;28:337-46.

17. Persavento G, Ferlito A, Fecher, G. Benign Mixed Tumours of Heterotrophic Salivary Gland Tissue in the Upper Neck. Report of a Case with the Review of Literature. J Laryngol Otol. 1976;9:577-84. 